\title{
Sleep and Stroke
}

\author{
Antonio Culebras, M.D. ${ }^{1}$
}

\section{ABSTRACT}

Sleep affects brain function and may contribute to vascular cerebral pathology through a diversity of direct and indirect mechanisms. Circadian rhythm investigation shows increased incidence of stroke between $6 \mathrm{AM}$ and 12 noon. Risk factors for stroke such as high blood pressure, ischemic heart disease, and diabetes are modified by sleep and sleep apnea. Epidemiological studies have shown a dose-response relationship between the severity of sleep apnea and the odds ratio for development of systemic hypertension. There is now evidence of a causal relationship between sleep apnea and stroke. Following stroke, both in the acute and chronic stages, patients have a high prevalence of sleep apnea that reduces the potential for rehabilitation, further increases the risk of secondary stroke, and heightens mortality. Successful correction of sleep apnea with noninvasive positive airway pressure ventilation lowers mean blood pressure, and indirectly lowers the risk of stroke. Unfortunately, patients with stroke tolerate positive noninvasive ventilation poorly, and other means of correcting sleep apnea need to be investigated.

KEYWORDS: Sleep apnea, stroke, positive noninvasive ventilation, hypertension, cardiovascular disease

Circadian variations that appear in consonance with sleep or sleep-related disorders may alter vascular function to the point of creating risk or provoking injury to the brain. ${ }^{1,2}$ The concept of an association between sleep and stroke comes primordially from the notion that sleep- disordered breathing, generically known as sleep apnea, is a risk factor for primary and secondary stroke. Much of this notion is derived from evidence implicating sleep apnea in the precipitation or aggravation of systemic hypertension and heart disease, ${ }^{3}$ both of which are established major risk factors for stroke. The prevalence of clinically significant sleep apnea in the general population has been estimated at $4 \%$ in men and $2 \%$ in women. ${ }^{4}$ Other mechanisms of sleep-related stroke risk include blood pressure swings in sleep, sleep apnearelated reduction of cerebral blood flow, changes in cerebral autoregulation, impaired endothelial function, accelerated atherogenesis, prothrombotic coagulation

\footnotetext{
${ }^{1}$ Department of Neurology, Upstate Medical University, Syracuse, New York.

Address for correspondence and reprint requests: Antonio Culebras, M.D., Professor of Neurology, Upstate Medical University, 750 E. Adams Street, Syracuse, NY 13210 (e-mail: aculebras@aol.com).
}

shifts, proinflammatory states, and increased platelet aggregation in sleep.

\section{CIRCADIAN VARIATIONS AND STROKE}

Various studies in different parts of the world have shown that the incidence of stroke peaks at the end of nocturnal sleep between 6:00 AM and 12:00 noon. ${ }^{1,2}$ The most critical period is one hour after awakening, whereas the least likely time for stroke occurrence is the late evening before midnight. Sympathetic activity decreases in non-rapid eye movement (NREM) sleep; parasympathetic activity tends to predominate, accounting for a reduction of heart rate, blood pressure, cardiac output, peripheral vascular resistance, and respiratory frequency. REM sleep is characterized by variability in the activity of both the sympathetic and parasympathetic systems with phasic oscillations and surges that result in a net
Clinical Sleep Neurology; Guest Editor, Alon Y. Avidan, M.D., M.P.H. Semin Neurol 2009;29:438-445. Copyright (C) 2009 by Thieme Medical Publishers, Inc., 333 Seventh Avenue, New York, NY 10001, USA. Tel: +1(212) 584-4662.

DOI 10.1055/s-0029-1237121. ISSN 0271-8235. 
increased parasympathetic tone and decreased sympathetic influence. In REM sleep, heart rate and arterial blood pressure variability are observed, while cerebral cortical and spinal blood flow increase. Fibrinolytic activity diminishes in the mornings, ${ }^{5}$ while platelet aggregability increases. ${ }^{6}$ These phenomena have been linked to augmented vascular morbidity during morning hours. The administration of aspirin fails to modify the circadian pattern of onset of stroke in the morning, suggesting that circadian-mediated hemodynamic factors are more important than rheologic and thrombotic factors.

\section{SLEEP AND CONVENTIONAL MAJOR RISK FACTORS FOR STROKE}

\section{Blood Pressure Changes}

Blood pressure (BP) levels and sleep are intimately linked. Physiologic and pathologic variations in $\mathrm{BP}$ are commonly observed in sleep. Certain BP variations are dependent on sleep stages; for instance, BP dips 10 to $15 \%$ in NREM sleep and is variable in REM sleep. Experimentally, NREM sleep can precipitate severe myocardial ischemia in a region of the heart supplied by coronary stenosis. ${ }^{7}$ Low blood pressure at night in vulnerable patients with altered vasomotor reflexes who take vasoactive medications has been implicated as a contributing factor in the development of thrombotic stroke. ${ }^{8}$ Absence of nocturnal blood pressure dipping, extreme dipping, or reversed dipping have been associated with increased prevalence of silent cerebral infarctions and strokes in older hypertensive patients. ${ }^{9}$ Deep and less-fragmented sleep is associated with more blood pressure dipping in normal subjects. ${ }^{10}$ Conversely, blood pressure normally surges in the morning. ${ }^{11}$ Morning hypertension is considered a strong independent predictor for future clinical stroke events in elderly hypertensive patients. ${ }^{12}$ Poor sleep quality is associated with prehypertension in healthy adolescents. The association is not explained by socioeconomic status, obesity, sleep apnea, or known comorbidities, suggesting that inadequate sleep quality is the critical factor associated with elevated blood pressure. ${ }^{13}$

\section{Diabetes}

Experimentally induced sleep deprivation in young men is associated with glucose intolerance, as well as with other alterations of endocrine function and metabolic regulation. ${ }^{14}$ Chronic inflammation has been proposed as one of the mechanisms linking sleep disturbances and new onset diabetes. ${ }^{15}$ New provocative research has linked sleep duration and diabetes type II. ${ }^{16}$ The authors examined the association between sleep duration and abnormal glucose tolerance, among 1336 men and
1434 women in Finland, aged 45 to 74 years. Oral glucose tolerance tests and sleep questionnaires were undertaken by all participants. The authors found an independent association between abnormal sleeping times and type 2 diabetes in middle-aged women. Even after adjustments for age, body mass index, sleep apnea probability, smoking, physical activity, and psychoactive medication, sleep duration of 6 hours or less or 8 hours or longer was independently associated with type 2 diabetes in women but not in men. The study was observational and limited by a low recruitment rate (62\%), only one measurement of blood glucose, and a self-reported questionnaire with polysomnographic confirmation. Nonetheless, the study provides strong indications of a link between sleep alterations and diabetes.

Several other studies have shown a relationship between sleep alteration and diabetes type II both in men ${ }^{17}$ and in women. ${ }^{18}$ In the Nurses Health Study of women, both increased ( $>8$ hours) and decreased $(<6$ hours) sleep times were associated with increased risk of diabetes. The adjusted OR of the incidence of diabetes was 1.18 for women sleeping less than 5 hours and 1.29 if sleeping more than 9 hours per night. Restricted sleep in healthy volunteers can lower glucose tolerance and increase sympathetic tone, both of which are risk factors for the development of insulin resistance. ${ }^{19}$

\section{SLEEP-RELATED FACTORS INCREASING THE RISK OF VASCULAR DISEASE}

\section{Snoring}

Pathologic snoring is the habitual harsh and loud vibratory sound produced by respiratory effort in the sleeping individual. Most persons past middle age exhibit some form of snoring, but only habitual, sustained, intensely loud snoring that is disturbing to others should be of importance to the clinician. Snoring of these characteristics is frequently a marker of obstructive sleep apnea disorder. Habitual snoring was associated in early studies with arterial hypertension, ${ }^{20}$ ischemic heart disease, ${ }^{21}$ and stroke. ${ }^{22}$ Epidemiologic studies have suggested that habitual snoring is a risk factor for brain infarction ${ }^{23}$ independent of confounding factors, such as hypertension, ischemic heart disease, obesity, and age. The association of snoring with obstructive sleep apnea disorder reinforces its weight as a risk factor. More recently, habitual snoring has been independently associated with hypertension in men and women. Kim et $\mathrm{al}^{24}$ studied 2730 men and 2723 women without obesity and hypertension at the time of their initial examinations. All participants were reevaluated after an interval of 2 years. Hypertension was defined on the basis of blood pressure equal or higher than $140 / 90 \mathrm{~mm} \mathrm{Hg}$ or the use of antihypertensive medications. Habitual snorers were defined as those who snored at least 4 days per week. 
The authors found that habitual snoring was independently associated with hypertension in men and women with odds ratios of 1.49 -fold and 1.56-fold at 2 years, respectively. Their results support the notion that habitual snoring is an important predisposing factor for development of high blood pressure, even for nonobese adults. The act of snoring implies great effort and force in the process of breathing. It is generally associated with arousals in the upper respiratory disturbance syndrome and with profound negative intrathoracic pressures that alter the hemodynamic function of the heart and may contribute to the risk of vascular disease.

\section{Sleep Apnea}

The hemodynamic consequences of sleep apnea and the pathophysiologic link between snoring and obstructive apneas were initially described in Italy by Lugaresi and coworkers $^{25}$ and Coccagna and collaborators. ${ }^{26}$ Sleep apnea may directly or indirectly increase the risk of stroke by increasing the odds of developing risk factors for stroke (i.e., high blood pressure) or aggravating comorbidities triggering stroke (i.e., atrial fibrillation). Other less well-assessed risk factors in sleep apnea are patent foramen ovale, impaired vascular endothelial function, accelerated atherogenesis, prothrombotic coagulation shifts, proinflammatory states, and increased platelet aggregation. But it was not until recently that direct evidence was uncovered of the link between sleep apnea and vascular events including stroke.

\section{SLEEP APNEA AND HYPERTENSION}

Transient elevations of systemic blood pressure reaching 200/100 mm Hg lasting a few seconds have been recorded in the recovery phase from apnea. This phenomenon has been attributed to the arousal that terminates the apnea event. The arousal is characterized polygraphically by a change in electroencephalogram (EEG) morphology and an enhancement of muscle tone that facilitates oropharyngeal dilator muscle function, a phenomenon responsible for overcoming the obstruction to air flow. Microneurography, a technique that evaluates autonomic discharges in nerves, has shown surges in sympathetic activity in association with arousals explaining the occurrence of blood pressure elevations and acceleration of the heart rate. Repeated bouts of hypertension night after night in patients with untreated sleep apnea may eventually lead to sustained hypertension through unknown mechanisms. ${ }^{27}$

Convincing evidence of an association between sleep apnea and sustained systemic hypertension, defined as a resting systolic pressure of $140 \mathrm{~mm} \mathrm{Hg}$ and a diastolic pressure of $90 \mathrm{~mm} \mathrm{Hg}$ or more, has been obtained. Results from the large community-based Sleep Heart Health Study ${ }^{28}$ indicate a dose-response relationship between sleep-disordered breathing and hyperten- sion. The study was conducted between 1995 and 1998 and included a total of 6132 subjects from which the apnea-hypopnea index (AHI) and other measures of disturbed sleep, including arousal index and percentage of sleep time below $90 \%$ oxygen saturation, were obtained by unattended home polysomnography. The odds ratio for development of hypertension comparing the highest category of AHI $(>30 / \mathrm{h})$ with the lowest category of AHI $(<1.5 / \mathrm{h})$ was 1.37 (CI 1.03-1.83), even after adjustment for confounding variables that included obesity and neck circumference. The adjusted odds of hypertension increased steadily with $\mathrm{AHI}$ values of $15 / \mathrm{h}$ to $20 / \mathrm{h}$ and higher, surpassing odds ratios of 2 for very high AHI values. A similar relation was obtained using as the reference parameter oxygen saturation measurements of $90 \%$ or less. Controlling for body mass index (BMI) diminished the strength of the association between sleep-disordered breathing and hypertension, suggesting that sleep apnea may be one of the intermediary mechanisms between obesity and hypertension.

The association between sleep apnea and hypertension was confirmed by the Wisconsin Sleep Cohort study ${ }^{29}$ and the Toronto study. ${ }^{30}$ In both investigations a dose-response relationship was uncovered between sleep-disordered breathing and hypertension, even after adjustment for confounding factors.

Morbidly obese patients with globular abdomens that challenge the mechanical activity of the diaphragm, the only functional respiratory muscle in REM sleep, exhibit the most profound oxygen desaturations in this stage in association with apnea events and arousals. ${ }^{31}$ The correlation between abdominal obesity and REM sleep-related apnea events and desaturations may explain, at least in part, the observed epidemiologic link between abdominal obesity and hypertension. ${ }^{32}$

\section{SLEEP APNEA AND HEART DISEASE}

Sleep apnea provokes cardiac dysrhythmias when there is concomitant cardiac or respiratory comorbidity. ${ }^{33}$ Patients with advanced sleep apnea may exhibit cardiac arrhythmias, such as atrioventricular block and atrial fibrillation, particularly when the oxyhemoglobin saturation falls below $65 \% .{ }^{34}$ Chronic and paroxysmal atrial fibrillation have been associated with sleep apnea. ${ }^{35-37}$ A high prevalence of sleep apnea is found in relatively young patients ( $56 \pm 12$ years) with both paroxysmal and persistent atrial fibrillation with normal left ventricular function, ${ }^{38}$ leading to the recommendation that relatively young individuals with atrial fibrillation should be investigated for the presence of sleep apnea. Obesity and the magnitude of nocturnal oxygen desaturation, which is an important pathophysiologic consequence of obstructive sleep apnea, are independent risk factors for atrial fibrillation in individuals $<65$ years of age. ${ }^{39}$ 
In an earlier study, ${ }^{40}$ the authors reported episodes of asystole lasting up to 9 seconds during phasic REM sleep in otherwise asymptomatic healthy young adults. They hypothesized that bursts of parasympathetic tone during phasic REM sleep reduced heart rate and played an important role in inducing asystole, a phenomenon that might be linked to unexplained sudden nocturnal death in vulnerable patients. Periods of asystole in REM sleep are of particular concern in patients with sleep apnea. ${ }^{41}$

In a study by Marin et $\mathrm{al}^{42}$ the effect of obstructive sleep apnea as a cardiovascular risk factor was investigated. The authors compared incidence of fatal and nonfatal cardiovascular events (myocardial infarction and stroke) in simple snorers, patients with untreated obstructive sleep apnea, patients treated with continuous positive airway pressure (CPAP), and healthy men. The presence and severity of the disorder was determined with full polysomnography. Participants were followed-up for a mean of 10.1 years (SD 1.6) and CPAP compliance was checked with a built-in meter. Multivariate analysis, adjusted for potential confounders, showed that untreated severe obstructive sleep apnea significantly increased the risk of fatal (OR $2.87,95 \%$ CI 1.17-7.51) and nonfatal (OR 3.17, 95\% CI 1.12-7.51) cardiovascular events compared with healthy participants, and suggested that CPAP treatment reduced the risk.

Sleep apnea is significantly associated with the risk of stroke among patients with coronary artery disease who are being evaluated for coronary intervention. ${ }^{43}$ The presence of patent foramen ovale (PFO) was studied with a transcranial Doppler technique in 78 consecutive patients with sleep apnea, and the results were compared with those obtained in age-matched controls. ${ }^{44}$ Twenty-seven percent of sleep apnea patients and $15 \%$ of control subjects had PFO. The authors concluded that the prevalence of patent foramen ovale is statistically higher $(p<0.05)$ in patients with sleep apnea, and suggested that the shunt may be open from right to left during brief Valsalva effects at the termination of sleep apneas. They hypothesized that patients with PFO have a higher risk of stroke due to paradoxical embolization.

\section{SLEEP APNEA AND CEREBRAL HEMODYNAMIC DYSFUNCTION}

Cerebral blood flow studies have shown that during the apnea event there is significant reduction in middle cerebral artery blood flow velocity. ${ }^{45}$ The drop correlates with the duration of the apnea rather than with the depth of oxyhemoglobin desaturation. The phenomenon suggests that hemodynamic disturbances consequent to thoracic negative pressures during obstructive apneas determine a reduction of cerebral blood flow. Intracranial hemodynamic changes occurring repeat- edly night after night in patients with marginal circulatory reserve may contribute to raise the risk of stroke, in particular in patients with significant sleep apnea disorder. ${ }^{46}$

When the cerebral circulation is compromised, hemodynamic changes may act as triggers of irreversible ischemic changes in regions with poor hemodynamic reserve, particularly borderzone areas and terminal artery territories. Preliminary studies of auditory event-related potentials in patients with treated sleep apnea found no improvement in abnormal P3 wave latencies, ${ }^{47}$ suggesting permanent structural changes in the white matter of the hemispheres, likely as a result of ischemia.

Healthy young children with apparently mild sleep-disordered breathing have potentially reversible cerebral hemodynamic and neurobehavioral changes following adenotonsillectomy, suggesting normalization of middle cerebral artery blood flow as measured with transcranial Doppler techniques. ${ }^{48,49}$

\section{SLEEP APNEA AND STROKE}

The specific risk of stroke or death in sleep apnea was investigated by Yaggi et al. ${ }^{50}$ In their study, the risk of stroke or death of any cause in patients with sleep apnea with a mean apnea/hypopnea index (AHI) of 35/hour was expressed by a hazards ratio of 2.24 (95\% CI 1.303.86). The increased risk was independent of other risk factors including hypertension. Increased severity of sleep apnea was associated with an incremental risk of stroke and death.

A causal association between sleep apnea and stroke was reinforced with recent work. In a study of 394 men aged 70 to 100 years, ${ }^{51}$ the authors concluded that severe obstructive sleep apnea/hypopnea (defined as AHI $\geq 30$ /hour) increases the risk of ischemic stroke in an elderly male noninstitutionalized population, independent of known confounding factors. In a prospective analysis of 1,189 subjects from the general population, ${ }^{52}$ the authors found that sleep-disordered breathing with an AHI of 20 or greater was associated with an increased risk of suffering a first-ever stroke over the next 4 years (unadjusted OR 4.31; 95\% CI 1.31-14.15; $p=0.02$ ). After adjustment for age, sex, and BMI, the odds ratio was still elevated, but was no longer significant (3.08; 95\% CI $0.74-12.81 ; p=0.12$ ). In a cross-sectional analysis of 1,475 individuals, the same authors found that subjects with an AHI of $20 /$ hour or greater had increased odds for stroke (OR 4.33; 95\% CI 1.32-14.24; $p=0.02)$ compared with those without sleep-disordered breathing (AHI <5) after adjustment for known confounding factors. The authors concluded that there is a strong association between moderate to severe sleepdisordered breathing and stroke, independent of confounding factors.

REM sleep is a most vulnerable time of the night because cerebral blood flow normally increases and 
cardiac rhythm variability is at a maximum. In sleep apnea patients, REM sleep-related atonia of dilator oropharyngeal muscles and loss of respiratory drive dependency on chemoreceptor reflex activity result in more prolonged episodes of obstructive apnea. In consequence, the accompanying hypoxemia is more profound and the cardiac rhythm changes more prominent, creating dissociation between an increasing demand and a progressively faltering supply of blood flow to the brain. ${ }^{31}$

There is some clinical evidence that small vessel disease and leukoaraiosis are worse in subjects with sleep apnea disorder. A higher prevalence of sleep apnea has been reported in patients with multi-infarct dementia compared with patients with Alzheimer's disease or control individuals of similar age. ${ }^{53}$ An association between sleep apnea and lacunar strokes has been reported. ${ }^{54}$ These observations support the hypothesis that brain regions with poor hemodynamic reserve are preferentially affected in sleep apnea, and coincide with reports of permanent alteration of auditory-event related potentials in these patients. The observations also suggest that early therapeutic intervention in sleep apnea is desirable.

Whether sleep apnea precedes the onset of stroke, occurs as a consequence of it, or both, remains an unresolved issue. In a polysomnographic study of $\mathrm{pa}^{-}$ tients 9 days poststroke or posttransient ischemic attack (TIA), ${ }^{55}$ the authors found a respiratory disturbance index of 10 /hour or more in $62.5 \%$ of subjects as opposed to $12.5 \%$ of controls. These results indicate that sleep apnea is common in the acute stages of stroke, but also suggest that sleep apnea may precede the onset of stroke, since TIA patients have a similar prevalence.

\section{Acute Stroke and Sleep}

Sleep apnea is frequent during the first 24 hours following stroke. ${ }^{56}$ In a polysomnographic study of 50 patients with acute hemispheric ischemic stroke, the authors found a sleep apnea prevalence of $62 \%$. Neurologic but not functional worsening was associated with the presence of sleep apnea. The study also showed a correlation between severity of sleep apnea and sleep-related onset of stroke. Bassetti et $\mathrm{al}^{57}$ found that sleep apnea is common, particularly in elderly stroke men with diabetes, nighttime stroke onset, and macroangiopathy as cause of stroke. They also found that sleep apnea improves after the acute phase, is associated with an increased poststroke mortality, and can be treated with CPAP in a small percentage of patients. Other authors ${ }^{58}$ have found that the severity of upper airway obstruction appears to be associated with a worse functional outcome following stroke, increasing the likelihood of death and dependency, and that longer respiratory events appear to have a greater effect.
Inversion of the sleep-wake rhythm may be observed in the days that follow a large hemispheric stroke and is manifested by agitation during the night and lethargy during the day, conditions that may be misinterpreted as signs of neurologic deterioration. The early presence of normal sleep cycles and generation of REM sleep are good prognostic signs. ${ }^{59}$ Location and extent of the stroke determines the type of sleep-related alteration. Respiratory dysfunction noted with infratentorial lesions include apneusis or apnea during sustained inspiration, nonobstructive, obstructive and mixed apneas, and failure of automatic breathing (Ondine's curse). ${ }^{60}$ In bilateral hemispheric lesions, Cheyne-Stokes respiration may be observed. ${ }^{60}$ The identification of clinically significant sleep apnea in patients with acute stroke is feasible with unattended stroke unit-based polysomnography or portable diagnostic systems. ${ }^{61}$ Sleep apnea events of the obstructive or nonobstructive varieties with oxyhemoglobin desaturations may require administration of oxygen through a nasal cannula or application of noninvasive positive airway pressure ventilation.

A study of sleep positions in patients with acute stroke showed that the vast majority of sleep time was spent supine. The majority (63\%) of subjects spent no time asleep in any of the nonsupine positions (prone, left, right). Given the high prevalence of supine sleep identified, positional therapy for acute stroke patients with sleep apnea may be warranted. ${ }^{62}$

Recent transcranial Doppler studies in patients with acute stroke suggest the possibility to detect and quantify cerebral steal in real-time, a phenomenon that describes recurrent hemodynamic and neurologic changes with persisting arterial occlusions attributable to cerebral blood flow steal from ischemic to nonaffected brain regions. This condition has been termed the reversed Robin Hood syndrome. ${ }^{63}$ If the steal is confirmed as the cause of neurologic worsening, reversed Robin Hood syndrome may identify a target group for blood pressure augmentation and noninvasive ventilatory correction in stroke patients. The condition may be particularly severe in patients with sleep apnea and stroke.

\section{Treatment of Sleep Apnea with Noninvasive Positive Airway Pressure Ventilation in Patients with Vascular Risk Factors or Stroke}

The treatment of sleep apnea has shifted from the early tracheotomies to the modern application of noninvasive continuous positive airway pressure (CPAP) ventilation, bilevel positive airway pressure ventilation, and more recently automatic control of airway pressure delivery with auto-CPAP devices. Successful treatment of sleep apnea reduces systemic hypertension and by inference the risk of stroke. ${ }^{64,65}$ 
Noninvasive ventilation reverses sleep-related desaturation of oxygen and hypercapnia in patients with acute stroke. It is also useful for management of congestive heart failure and Cheyne-Stokes respirations. Unfortunately, the data relative to acute stroke patients is not conclusive, albeit highly suggestive of a favorable effect. $^{57}$

\section{STROKE REHABILITATION AND SLEEP}

The prevalence of sleep-disordered breathing is high during the rehabilitation period following stroke. In an overnight study with continuous computerized oxymetry and polysomnography in selected cases, ${ }^{66}$ the authors found that $19 \%$ of patients had more than 100 desaturation events on the night of recording. Patients with 10 episodes or more of desaturation per hour of sleep had significantly lower Barthel Index scores on discharge and at 3 months and 12 months poststroke. Mortality was associated with oxymetry variables, indicating increased percentage of time spent below $90 \%$ saturation. The study suggested that oxymetry values compatible with sleep apnea in patients in rehabilitation from stroke were associated with worse functional outcome and higher mortality rates.

Other studies ${ }^{67-69}$ have pointed out repeatedly that patients poststroke have a high prevalence of sleepdisordered breathing $\left(71 \%,{ }^{69} 77 \%{ }^{68}\right)$ and that optimal rehabilitation potential and even survival may be compromised. Patients with stroke and obstructive sleep apnea had an increased risk of early death in the study by Sahlin et al. ${ }^{70}$ Patients were followed for up to 10 years, and central sleep apnea was excluded as a risk factor. The risk of death was higher among patients with obstructive sleep apnea than controls (adjusted HR 1.76; $95 \%$ CI 1.05-2.95; $p=0.03$ ) and was independent of age, sex, BMI, smoking, hypertension, diabetes mellitus, atrial fibrillation, Mini-Mental State Examination score, and Barthel Index.

Sleep apnea reduces motivation and decreases cognitive capacity while increasing the risk of stroke and death. The application of noninvasive positive airway pressure ventilation offers a window of opportunity to patients with sleep apnea to increase the rehabilitation potential poststroke. Unfortunately, CPAP compliance has not been good in patients recovering from stroke, and beneficial effects have not been confirmed. ${ }^{71}$ Subject dropout was related to difficulties with CPAP usage, facial weakness, motor impairment, and discomfort with usage of full-face mask. In the study by Palombini et al, ${ }^{72}$ the majority of sleep apnea stroke patients rejected CPAP treatment. The authors concluded that better education and support of patients and families, and special training sessions in rehabilitation services, will be needed to improve compliance.

\section{REFERENCES}

1. Marler JR, Price TR, Clark GL, et al. Morning increase in onset of ischemic stroke. Stroke 1989;20(4):473-476

2. Marsh EE III, Biller J, Adams HP Jr, et al. Circadian variation in onset of acute ischemic stroke. Arch Neurol 1990;47(11):1178-1180

3. Culebras A. Cerebrovascular disease and sleep. Curr Neurol Neurosci Rep 2004;4(2):164-169

4. Young T, Palta M, Dempsey J, Skatrud J, Weber S, Badr S. The occurrence of sleep-disordered breathing among middleaged adults. N Engl J Med 1993;328(17):1230-1235

5. Andreotti F, Davies GJ, Hackett DR, et al. Major circadian fluctuations in fibrinolytic factors and possible relevance to time of onset of myocardial infarction, sudden cardiac death and stroke. Am J Cardiol 1988;62(9):635-637

6. Tofler GH, Brezinski D, Schafer AI, et al. Concurrent morning increase in platelet aggregability and the risk of myocardial infarction and sudden cardiac death. N Engl J Med 1987;316(24):1514-1518

7. Kim SJ, Kuklov A, Kehoe RF, Crystal GJ. Sleep-induced hypotension precipitates severe myocardial ischemia. Sleep 2008;31(9):1215-1220

8. Argentino C, Toni D, Rasura M, et al. Circadian variation in the frequency of ischemic stroke. Stroke 1990;21(3):387389

9. Kario K, Pickering TG, Matsuo T, Hoshide S, Schwartz JE, Shimada K. Stroke prognosis and abnormal nocturnal blood pressure falls in older hypertensives. Hypertension 2001; 38(4):852-857

10. Loredo JS, Nelesen R, Ancoli-Israel S, Dimsdale JE. Sleep quality and blood pressure dipping in normal adults. Sleep 2004;27(6):1097-1103

11. Giles TD. Circadian rhythm of blood pressure and the relation to cardiovascular events. J Hypertens Suppl 2006;24(2):S11S16

12. Kario K, Ishikawa J, Pickering TG, et al. Morning hypertension: the strongest independent risk factor for stroke in elderly hypertensive patients. Hypertens Res 2006;29(8):581587

13. Javaheri S, Storfer-Isser A, Rosen CL, Redline S. Sleep quality and elevated blood pressure in adolescents. Circulation 2008;118(10):1034-1040

14. Spiegel K, Leproult R, Van Cauter E. Impact of sleep debt on metabolic and endocrine function. Lancet 1999;354(9188): 1435-1439

15. Vgontzas AN, Papanicolaou DA, Bixler EO, et al. Sleep apnea and daytime sleepiness and fatigue: relation to visceral obesity, insulin resistance, and hypercytokinemia. J Clin Endocrinol Metab 2000;85(3):1151-1158

16. Tuomilehto H, Peltonen M, Partinen M, et al. Sleep duration is associated with an increased risk for the prevalence of type 2 diabetes in middle-aged women - The FIN-D2D survey. Sleep Med 2008;9(3):221-227

17. Gottlieb DJ, Punjabi NM, Newman AB, et al. Association of sleep time with diabetes mellitus and impaired glucose tolerance. Arch Intern Med 2005;165(8):863-867

18. Ayas NT, White DP, Al-Delaimy WK, et al. A prospective study of self-reported sleep duration and incident diabetes in women. Diabetes Care 2003;26(2):380-384

19. Reaven GM, Lithell H, Landsberg L. Hypertension and associated metabolic abnormalities - the role of insulin resistance and the sympathoadrenal system. N Engl J Med 1996;334(6):374-381 
20. Lindberg E, Janson C, Gislason T, Svärdsudd K, Hetta J, Boman G. Snoring and hypertension: a 10 year follow-up. Eur Respir J 1998;11(4):884-889

21. Koskenvuo M, Kaprio J, Telakivi T, Partinen M, Heikkilä K, Sarna S. Snoring as a risk factor for ischaemic heart disease and stroke in men. Br Med J (Clin Res Ed) 1987;294(6563): 16-19

22. Palomäki H, Partinen $M$, Erkinjuntti $T$, Kaste $M$. Snoring, sleep apnea syndrome, and stroke. Neurology 1992;42(7, Suppl 6):75-81; discussion 82

23. Partinen M, Palomäki H. Snoring and cerebral infarction. Lancet 1985;2(8468):1325-1326

24. Kim J, Yi H, Shin KR, Kim JH, Jung KH, Shin C. Snoring as an independent risk factor for hypertension in the nonobese population: the Korean Health and Genome Study. Am J Hypertens 2007;20(8):819-824

25. Lugaresi E, Coccagna G, Mantovani M, Cirignotta F, Ambrosetto G, Baturic P. Hypersomnia with periodic breathing: periodic apneas and alveolar hypoventilation during sleep. Bull Physiopathol Respir (Nancy) 1972;8(5): 1103-1113

26. Coccagna G, Mantovani M, Brignani F, Parchi C, Lugaresi E. Continuous recording of the pulmonary and systemic arterial pressure during sleep in syndromes of hypersomnia with periodic breathing. Bull Physiopathol Respir (Nancy) 1972;8(5):1159-1172

27. Narkiewicz K, Somers VK. The sympathetic nervous system and obstructive sleep apnea: implications for hypertension. J Hypertens 1997;15(12 Pt 2):1613-1619

28. Nieto FJ, Young TB, Lind BK, et al. Association of sleepdisordered breathing, sleep apnea, and hypertension in a large community-based study. Sleep Heart Health Study. JAMA 2000;283(14):1829-1836

29. Peppard PE, Young T, Palta M, Skatrud J. Prospective study of the association between sleep-disordered breathing and hypertension. N Engl J Med 2000;342(19):1378-1384

30. Lavie P, Herer P, Hoffstein V. Obstructive sleep apnoea syndrome as a risk factor for hypertension: population study. BMJ 2000;320(7233):479-482

31. Culebras A. REM-sleep related diaphragmatic insufficiency. Neurology 1998;50(suppl 4):393-394

32. Okosun IS, Prewitt TE, Cooper RS. Abdominal obesity in the United States: prevalence and attributable risk of hypertension. J Hum Hypertens 1999;13(7):425-430

33. Flemons WW, Remmers JE, Gillis AM. Sleep apnea and cardiac arrhythmias. Is there a relationship? Am Rev Respir Dis 1993;148(3):618-621

34. Guilleminault C, Connolly SJ, Winkle RA. Cardiac arrhythmia and conduction disturbances during sleep in 400 patients with sleep apnea syndrome. Am J Cardiol 1983; 52(5):490-494

35. Mooe T, Gullsby S, Rabben T, Eriksson P. Sleep-disordered breathing: a novel predictor of atrial fibrillation after coronary artery bypass surgery. Coron Artery Dis 1996;7(6):475-478

36. Gami AS, Somers VK. Implications of obstructive sleep apnea for atrial fibrillation and sudden cardiac death. J Cardiovasc Electrophysiol 2008;19(9):997-1003

37. Braga B, Poyares D, Cintra F, et al. Sleep-disordered breathing and chronic atrial fibrillation. Sleep Med 2009; 10(2):212-216

38. Stevenson IH, Teichtahl H, Cunnington D, Ciavarella S, Gordon I, Kalman JM. Prevalence of sleep disordered breathing in paroxysmal and persistent atrial fibrillation patients with normal left ventricular function. Eur Heart J 2008;29(13):1662-1669

39. Gami AS, Hodge DO, Herges RM, et al. Obstructive sleep apnea, obesity, and the risk of incident atrial fibrillation. J Am Coll Cardiol 2007;49(5):565-571

40. Guilleminault C, Pool P, Motta J, Gillis AM. Sinus arrest during REM sleep in young adults. N Engl J Med 1984; 311(16):1006-1010

41. Culebras A. Stroke and sleep disorders. In: Fisher M, Bogousslavsky J, eds. Current Review of Cerebrovascular Disease. 2nd ed. Philadelphia: Current Medicine; 1996

42. Marin JM, Carrizo SJ, Vicente E, Agusti AG. Long-term cardiovascular outcomes in men with obstructive sleep apnoea-hypopnoea with or without treatment with continuous positive airway pressure: an observational study. Lancet 2005;365(9464):1046-1053

43. Valham F, Mooe T, Rabben T, Stenlund H, Wiklund U, Franklin KA. Increased risk of stroke in patients with coronary artery disease and sleep apnea: a 10-year follow-up. Circulation 2008;118(9):955-960

44. Beelke M, Angeli S, Del Sette M, et al. Prevalence of patent foramen ovale in subjects with obstructive sleep apnea: a transcranial Doppler ultrasound study. Sleep Med 2003;4(3): 219-223

45. Netzer N, Werner P, Jochums I, Lehmann M, Strohl KP. Blood flow of the middle cerebral artery with sleepdisordered breathing: correlation with obstructive hypopneas. Stroke 1998;29(1):87-93

46. Jiménez PE, Coloma R, Segura T. [Brain haemodynamics in obstructive sleep apnea syndrome]. Rev Neurol 2005; 41(Suppl 3):S21-S24

47. Sangal RB, Sangal JM. Abnormal visual P300 latency in obstructive sleep apnea does not change acutely upon treatment with CPAP. Sleep 1997;20:702-704

48. Hill CM, Hogan AM, Onugha N, et al. Increased cerebral blood flow velocity in children with mild sleep-disordered breathing: a possible association with abnormal neuropsychological function. Pediatrics 2006;118(4):e1100-e1108

49. Hogan AM, Hill CM, Harrison D, Kirkham FJ. Cerebral blood flow velocity and cognition in children before and after adenotonsillectomy. Pediatrics 2008;122(1):75-82

50. Yaggi HK, Concato J, Kernan WN, Lichtman JH, Brass LM, Mohsenin V. Obstructive sleep apnea as a risk factor for stroke and death. N Engl J Med 2005;353(19):20342041

51. Muñoz R, Durán-Cantolla J, Martínez-Vila E, et al. Severe sleep apnea and risk of ischemic stroke in the elderly. Stroke 2006;37(9):2317-2321

52. Arzt M, Young T, Finn L, Skatrud JB, Bradley TD. Association of sleep-disordered breathing and the occurrence of stroke. Am J Respir Crit Care Med 2005;172(11):14471451

53. Erkinjuntti T, Partinen M, Sulkava R, Telakivi T, Salmi T, Tilvis R. Sleep apnea in multiinfarct dementia and Alzheimer's disease. Sleep 1987;10(5):419-425

54. Harbison J, Ford GA, James OF, Gibson GJ. Sleepdisordered breathing following acute stroke. QIM 2002; 95(11):741-747

55. Bassetti C, Aldrich MS. Sleep apnea in acute cerebrovascular diseases: final report on 128 patients. Sleep 1999;22(2):217223

56. Iranzo A, Santamaría J, Berenguer J, Sánchez M, Chamorro A. Prevalence and clinical importance of sleep apnea in the 
first night after cerebral infarction. Neurology 2002;58(6): 911-916

57. Bassetti CL, Milanova M, Gugger M. Sleep-disordered breathing and acute ischemic stroke: diagnosis, risk factors, treatment, evolution, and long-term clinical outcome. Stroke 2006;37(4):967-972

58. Turkington PM, Allgar V, Bamford J, Wanklyn P, Elliott MW. Effect of upper airway obstruction in acute stroke on functional outcome at 6 months. Thorax 2004;59(5):367-371

59. Giubilei F, Iannilli M, Vitale A, et al. Sleep patterns in acute ischemic stroke. Acta Neurol Scand 1992;86(6):567-571

60. Vingerhoets F, Bogousslavsky J. Respiratory dysfunction in stroke. Clin Chest Med 1994;15(4):729-737

61. Broadley SA, Jørgensen L, Cheek A, et al. Early investigation and treatment of obstructive sleep apnoea after acute stroke. J Clin Neurosci 2007;14(4):328-333

62. Brown DL, Lisabeth LD, Zupancic MJ, Concannon M, Martin C, Chervin RD. High prevalence of supine sleep in ischemic stroke patients. Stroke 2008;39(9):2511-2514

63. Alexandrov AV, Sharma VK, Lao AY, Tsivgoulis G, Malkoff $\mathrm{MD}$, Alexandrov AW. Reversed Robin Hood syndrome in acute ischemic stroke patients. Stroke 2007;38(11):3045-3048

64. Pepperell JCT, Ramdassingh-Dow S, Crosthwaite N, et al. Ambulatory blood pressure after therapeutic and subtherapeutic nasal continuous positive airway pressure for obstructive sleep apnoea: a randomised parallel trial. Lancet 2002;359(9302):204-210
65. Becker HF, Jerrentrup A, Ploch T, et al. Effect of nasal continuous positive airway pressure treatment on blood pressure in patients with obstructive sleep apnea. Circulation 2003;107(1):68-73

66. Good DC, Henkle JQ, Gelber D, Welsh J, Verhulst S. Sleep-disordered breathing and poor functional outcome after stroke. Stroke 1996;27(2):252-259

67. Dyken ME, Somers VK, Yamada T, Ren ZY, Zimmerman MB. Investigating the relationship between stroke and obstructive sleep apnea. Stroke 1996;27(3):401-407

68. Mohsenin V, Valor R. Sleep apnea in patients with hemispheric stroke. Arch Phys Med Rehabil 1995;76(1): 71-76

69. Parra O, Arboix A, Bechich S, et al. Time course of sleeprelated breathing disorders in first-ever stroke or transient ischemic attack. Am J Respir Crit Care Med 2000;161 (2 Pt 1):375-380

70. Sahlin C, Sandberg O, Gustafson Y, et al. Obstructive sleep apnea is a risk factor for death in patients with stroke: a 10-year follow-up. Arch Intern Med 2008;168(3):297-301

71. Hsu CY, Vennelle M, Li HY, Engleman HM, Dennis MS, Douglas NJ. Sleep-disordered breathing after stroke: a randomised controlled trial of continuous positive airway pressure. J Neurol Neurosurg Psychiatry 2006;77(10):11431149

72. Palombini L, Guilleminault C. Stroke and treatment with nasal CPAP. Eur J Neurol 2006;13(2):198-200 